\title{
A Study on Correlation between Liquid Limit by Cone Penetrometer and Casagrande Method
}

\author{
M. A. Kumbhar ${ }^{1}$, A. S. Shelke ${ }^{2}$, A. D. Kadam ${ }^{3}$, R. R. Maske ${ }^{4}$ \\ 1, 2, 3, 4 Third Year students of Civil Engineering Department, Anantrao Pawar College of Engineerinng and Research, Parvati \\ Pune.411009. (India)
}

\begin{abstract}
Soil quality is a major factor that affects the stability and durability of any structure. Various properties of soil like liquid limit, plastic limit, liquidity index, plasticity index, etc. determine the quality of soil. In this paper the experimental work in the field of evaluation the liquid limit is described. Five different types of soil were analyzed. Two basic methods were used for the evaluation of the liquid limit - Casagrande percussion (cup) method and cone penetrometer method. The paper presents the correlation between liquid limit by Casagrande percussion method and liquid limit by cone penetrometer method and a mathematical relation is established between the two methods.
\end{abstract}

Keywords: Correlation, Casagrande, Cone-Penetrometer, Liquid Limit, Equation, Plastic Limit

\section{Introduction}

Liquid limit of soil is a very important property of fine grained soil (or cohesive soil).Value of liquid limit is used to classify fine grained soil. It gives information regarding the state of consistency of soil on site. It can be used to predict the consolidation properties of soil while calculating allowable bearing capacity and settlement of foundation and to calculate activity of clays and toughness index of soil. Liquid limit is the water content corresponding to arbitrary limit between liquid and plastic state of consistency of soil. The minimum water content at which the soil is still in liquid state, but has small shearing strength against flowing which can be measured by standard available mean. It can measured by two methods:

a) Casagrande Apparatus

b) Cone Penetrometer

\section{Experimental Methods For Liquid Limit De- termination}

The study was realized by exploitation of the antecedently mentioned laboratory strategies for liquid limit determination. Normal Casagrande methodology uses a typical metal cup, within which a soil paste is placed, then the soil is split by cutting a groove of normal dimension and also the cup is drop on a base fabricated from a typical material. The liquid limit is outlined because the water content of the soil such as the closing of groove on a length of 12.5 millimeter resulted from the impact of twenty five blows of Casagrande cup.

The cone penetrometer technique is predicated on the relation between shear strength and penetration resistant and uses the free falling cone (standard cone has weight eighty grams with apex angle of $30^{\circ}$ ). According this customary the liquid limit of the soil is outlined because the water content equivalent to cone penetration of twenty millimeter

But the above mentioned strategies for the determination of the liquid limit have some limitations. Casagrande method could be a dynamic shear method and its results is also stricken by several objective and subjective factors, among others, by the variations in behavior in response to shaking. This method is additionally terribly sensitive to the operator technique.

The cone penetrometer method is a smaller amount long and easier as compared with the cup check and it permits to eliminate the judgment related to the Casagrande cup method. However the methodology of this method, supported the Hansbo ${ }^{[3]}$ and Houlsby ${ }^{[4]}$ theory, assumed a continuing undrained shear strength of $1.7 \mathrm{kPa}$ like the liquid limit for all kind of soils. According Hansbo theory the undrained shear strength cu is reciprocally proportional to the sq. of the cone penetration $d$ and might be expressed within the kind (1):

$$
\mathrm{C}_{\mathbf{u}}=\mathrm{k} \cdot(\mathrm{g} \cdot \mathrm{w}) / \mathbf{d}^{2}
$$

Where $\mathrm{W}$ is weight of the cone, $\mathrm{g}$ is gravity acceleration $(9.81 \mathrm{~m} / \mathrm{s} 2), \mathrm{d}$ is depth of penetration and $\mathrm{k}$ is constant looking on cone pure mathematics (for the quality cone $30 \% / 80 \mathrm{~g}$ this constant $\mathrm{k}=0.867([7]))$.

\section{Experimental Works}

The experiment was carried by performing Casagrande Apparatus and cone penetrometer. These two test were performed on 5 different types of soil as follows:

1) Red Soil

2) Impure Black Cotton Soil

3) Pure Black Cotton Soil

4) White Soil

5) Alluvial Soil

\subsection{Laboratory Analysis}

3.1.1 Liquid Limit (IS 2720-V)

The liquid limit measured by cone penetration for each soil sample as per IS. 2720 Part V 
a)

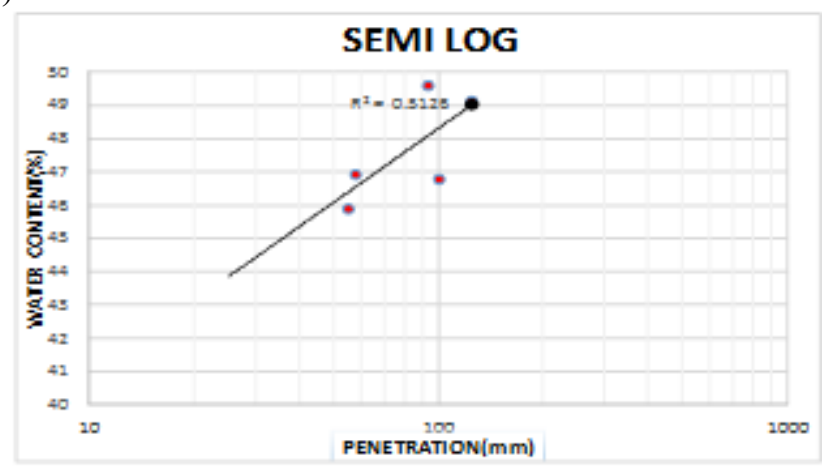

Graph 1: Liquid limit for RED SOIL

By Cone penetration liquid limit of Red soil is found. The above graph shows the relation between penetration and water content.

$\mathrm{LL}=44.3 \%$

b)

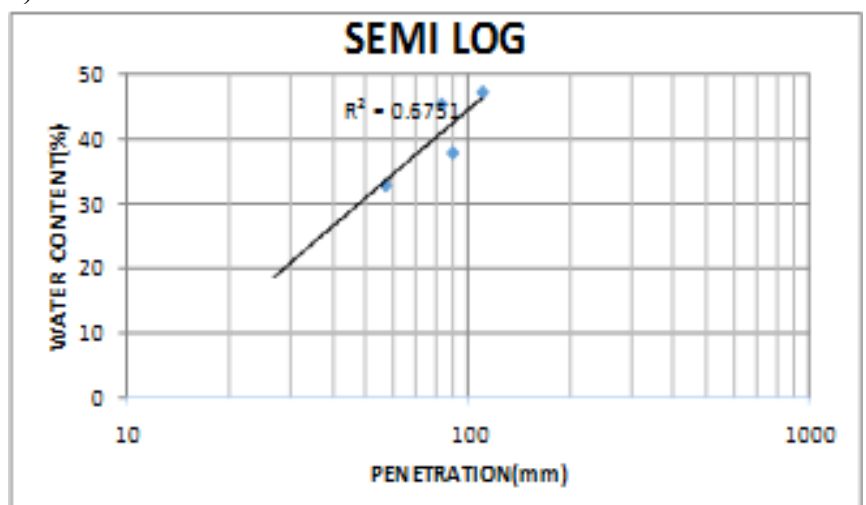

Graph 2: Liquid limit for IMPURE BLACK COTTON SOIL

By Cone penetration liquid limit of Impure black cotton soil is found. The above graph shows the relation between penetration and water content.

$\mathrm{LL}=22 \%$

c)

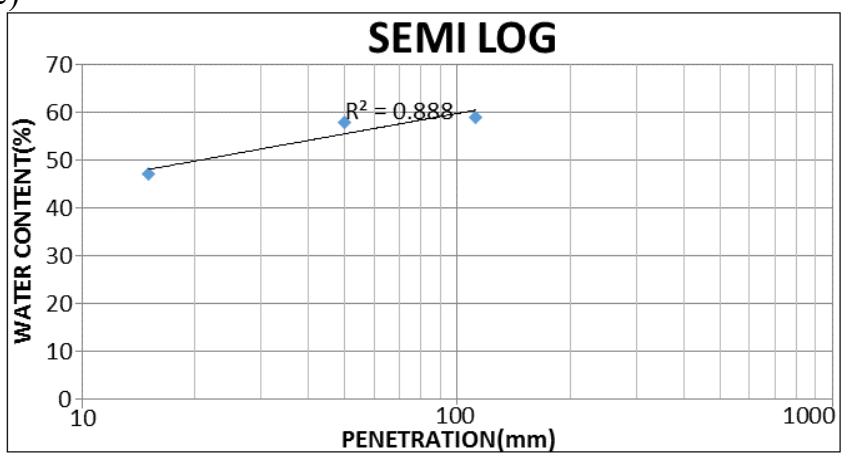

Graph 3: Liquid limit for PURE BLACK COTTON SOIL

By Cone penetration liquid limit of pure black cotton soil is found. The above graph shows the relation between penetration and water content. $\mathrm{LL}=53 \%$

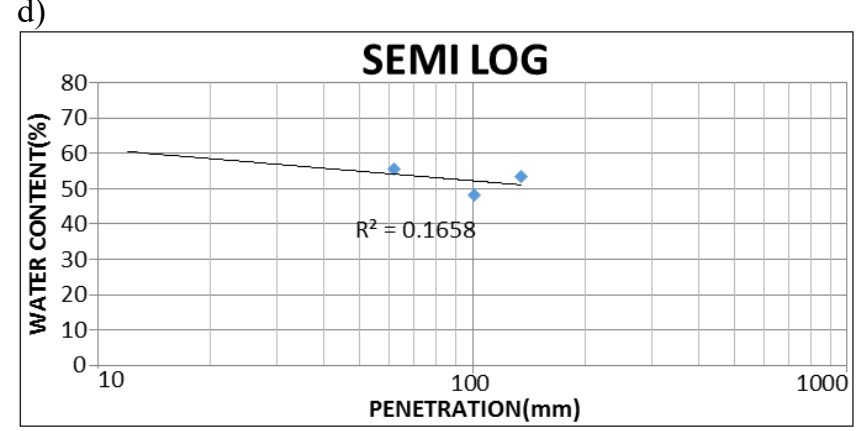

Graph 4: Liquid limit for WHITE SOIL

By Cone penetration liquid limit of White soil is found. The above graph shows the relation between penetration and water content. $\mathrm{LL}=57 \%$

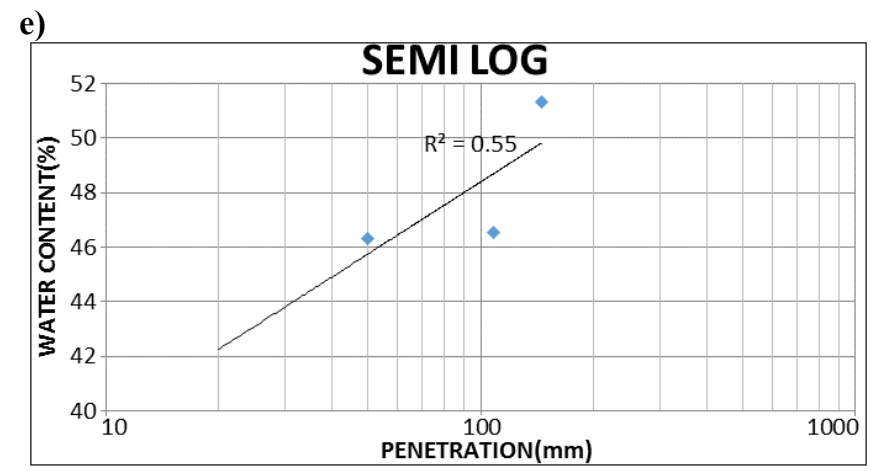

Graph 5: Liquid limit for ALLUVIAL SOIL

By Cone penetration liquid limit of Alluvial soil is found. The above graph shows the relation between penetration and water content.

$\mathrm{LL}=44 \%$

The liquid limit measured by casagrande for each soil sample as per IS. 2720 Part V

f)

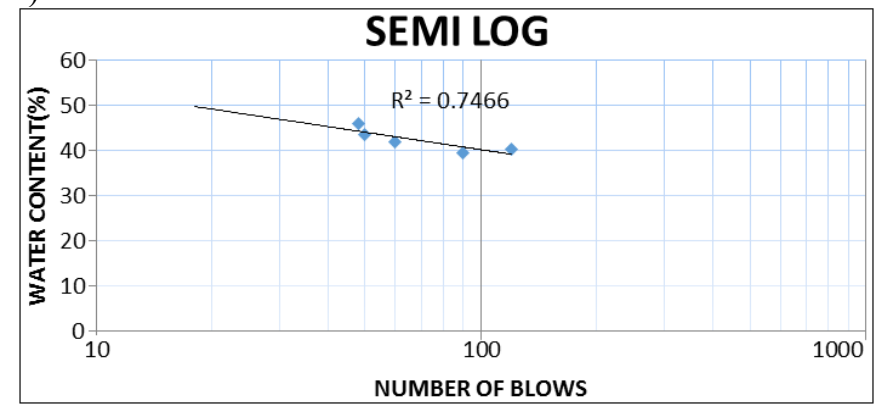

Graph 6: Liquid limit for RED SOIL

By Casagrande liquid limit of red soil is found. The above graph shows the relation between no. of blows and water content. $\mathrm{LL}=46 \%$ 
International Journal of Science and Research (IJSR)

ISSN (Online): 2319-7064

Index Copernicus Value (2015): 78.96 | Impact Factor (2015): 6.391

g)

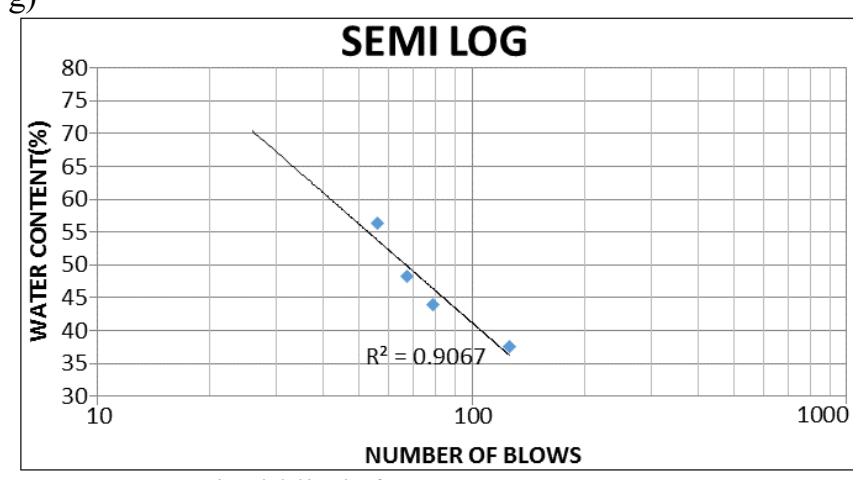

Graph 7: Liquid limit for IMPURE BLACK COTTON SOIL

By Casagrande liquid limit of Impure black cotton soil is found. The above graph shows the relation between no. of blows and water content. $\mathrm{LL}=64 \%$

h)

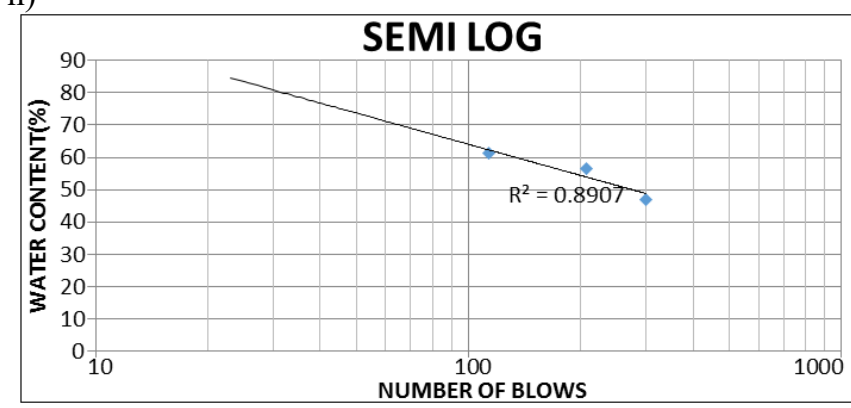

Graph 8: Liquid limit for PURE BLACK COTTON SOIL

By Casagrande liquid limit of Pure black cotton soil is found. The above graph shows the relation between no. of blows and water content. $\mathrm{LL}=78 \%$

i)

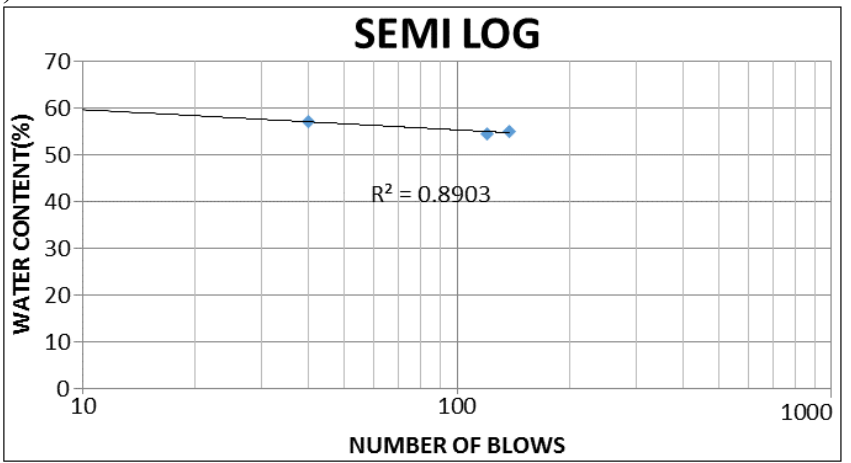

Graph 9: Liquid limit for WHITE SOIL

By Casagrande liquid limit of White soil is found. The above graph shows the relation between no. of blows and water content.LL $=58 \%$

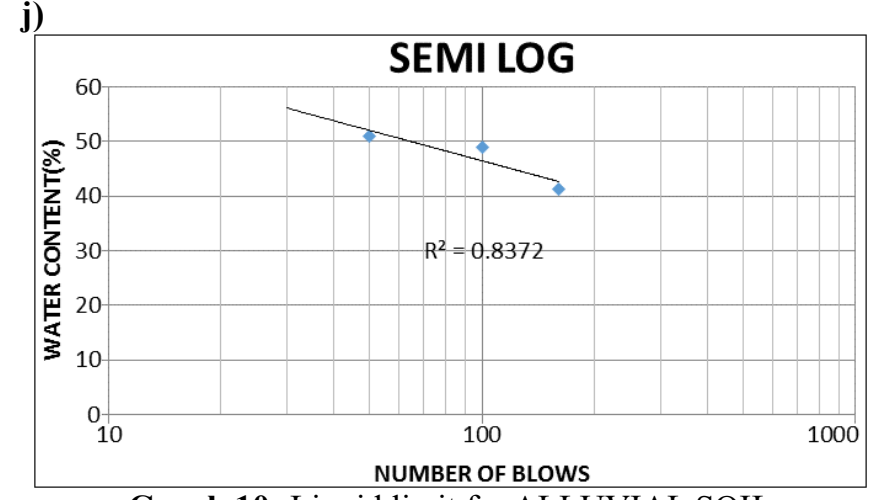

Graph 10: Liquid limit for ALLUVIAL SOIL

By Casagrande liquid limit of Alluvial soil is found. The above graph shows the relation between no. of blows and water content.

$\mathrm{LL}=55 \%$

\subsubsection{Correlation between LL from Cassagrand appara-} tus and $L L$ from Cone Penetration

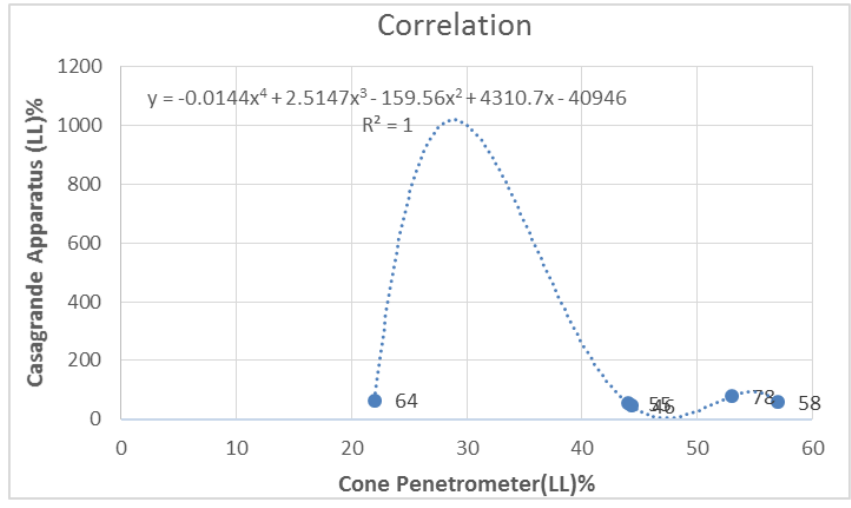

Graph 11: Correlation of casagrande apparaturs and cone penetrometer

\section{Result}

The following table shows calculation of Correlation between LL by casagrande apparatus and by Cone Penetrometer.

Table 1: Correlation

\begin{tabular}{|c|c|c|c|c|}
\hline \multirow{2}{*}{$\begin{array}{c}\text { S. } \\
\text { No }\end{array}$} & Soil & \multicolumn{3}{|c|}{ Liquid Limit } \\
\cline { 3 - 5 } & $\begin{array}{c}\text { Casagrande } \\
\text { Method (\%) }\end{array}$ & $\begin{array}{c}\text { Cone Penetration } \\
\text { Method (\%) }\end{array}$ & $\begin{array}{c}\text { Correlation } \\
(\mathrm{y}) \%\end{array}$ \\
\hline 1 & Red Soil & 46 & 44.3 & 47.18141146 \\
\hline 2 & $\begin{array}{c}\text { mpure Black } \\
\text { Cotton Soil }\end{array}$ & 64 & 22 & 65.5992 \\
\hline & $\begin{array}{c}\text { Pure Black } \\
\text { Cotton Soil }\end{array}$ & 78 & 53 & 75.1255 \\
\hline 4 & White soil & 58 & 57 & 51.8827 \\
\hline 5 & Alluvial Soil & 55 & 44 & 56.2624 \\
\hline
\end{tabular}

\section{Conclusion}

By correlating the values of liquid limit by Casagrande Apparatus and Cone Penetrometer following equation has been obtained

$$
\begin{aligned}
& y=-0.0144 x^{4}+2.5147 x^{3}-159.56 x^{2}+4310.7 x-40946 \\
& y=\text { Liquid Limit By casagrande Apparatus } \\
& \mathrm{x}=\text { Liquid limit by cone penetrometer }
\end{aligned}
$$




\section{References}

[1] Casagrande, A. Research on the Atterberg limits of soil. Public Roads 13(8). pp.121-130.

[2] Houlsby,G.T. Theoretical analysis of the fall cone test. Geotechnique. Vol. 32(2). pp.111-118.

[3] Hansbo,S. A new approach to the determination of the shear strength of clay by the fall-cone test. In: Proc. of the Royal Swedish Geotechnical Institute. No. 14. pp.4-47.

[4] Dr. B.C. Punmia, Ashok Kumar Jain and Arun Kumar Jain. Soil Mechanics

[5] IS: 2720 Part V (1965). Determination of Liquid Limit and Plastic Limit

[6] Norman LEJ (1958). A comparison of values of liquid limit determined with apparatus having bases of different hardness. Geotechinque 8:79-83

[7] Wroth,C.P., Wood,D.M. The correlation of index properties with some basic engineering properties of soils. Canadian Geotechnical Journal. Vol.15(2). pp.137-145.

[8] Wood, K.M. Cone penetrometer and liquid limit. Geotechnique. Vol. 32 (2).pp.152-157. 